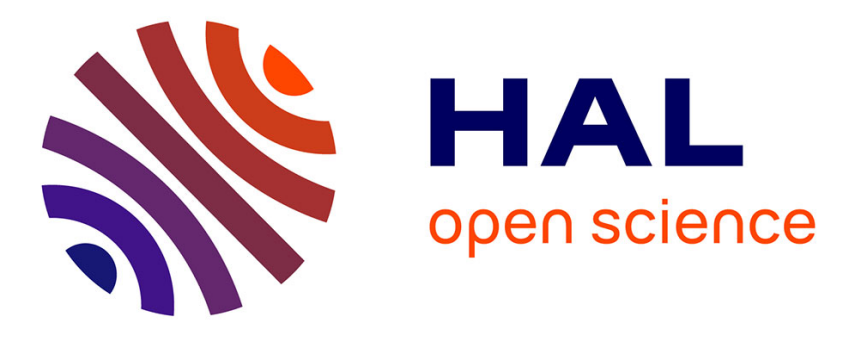

\title{
Microbial enzymatic assays in environmental water samples: Impact of inner filter effect and substrate concentrations
}

Marion Urvoy, Claire Labry, Daniel Delmas, Layla Creac'H, Stéphane L'Helguen

\section{To cite this version:}

Marion Urvoy, Claire Labry, Daniel Delmas, Layla Creac'H, Stéphane L'Helguen. Microbial enzymatic assays in environmental water samples: Impact of inner filter effect and substrate concentrations. Limnology and Oceanography: Methods, 2020, 18, pp.725-738. 10.1002/lom3.10398 . hal-02989835

\section{HAL Id: hal-02989835 https://hal.science/hal-02989835}

Submitted on 19 Nov 2020

HAL is a multi-disciplinary open access archive for the deposit and dissemination of scientific research documents, whether they are published or not. The documents may come from teaching and research institutions in France or abroad, or from public or private research centers.
L'archive ouverte pluridisciplinaire HAL, est destinée au dépôt et à la diffusion de documents scientifiques de niveau recherche, publiés ou non, émanant des établissements d'enseignement et de recherche français ou étrangers, des laboratoires publics ou privés. 
$1 \quad$ Microbial enzymatic assays in environmental water samples: impact of Inner

3 Urvoy M. ${ }^{1,2 *}$, Labry C. ${ }^{1}$, Delmas D. ${ }^{1}$, Creac'h L. ${ }^{1}$, L’Helguen S. $^{2}$

4 'Ifremer, DYNECO, F-29280 Plouzané, France

$5 \quad *$ Correspondence: murvoy@ifremer.fr

$6 \quad$ 2Univ Brest, CNRS, IRD, Ifremer, LEMAR, F-29280 Plouzané, France

7 Running head

$8 \quad$ Enzymatic assays in environmental water samples

$9 \quad$ Key words

10 Microbial enzymatic activities, Fluorimetry, Inner Filter Effect, Biogeochemical studies 


\section{Abstract}

12 As microbial enzymatic activities initiate the mineralization of organic matter through the microbial loop, it is important to correctly measure those activities and be able to perform inter-study comparisons. Enzymatic activity assays are typically carried out using fluorogenic substrate analogs, such as 4Methylumbelliferone and 7-Amino-4-methylcoumarin linked to sugar monomers, phosphate group or amino acids. However, methodological divergences can be found in aquatic science literature, potentially leading to misestimated activities. To highlight some of those methodological key points, we first addressed the potential occurrence of an Inner Filter Effect (IFE), a fluorometric artifact that affects the relationship between fluorophore concentration and fluorescence intensity, due to absorption of exciting or emitted light. It has never been considered in the context of environmental waterstudies before, despite significantly affecting measured activities. IFE occurred with 2 out of 3 tested spectrofluorometers when assaying proteases, although no IFE was detected for phosphatase assays. We also evaluated how substrate concentration ranges might affect kinetic parameters estimation, revealing that a many existing studies might use insufficient maximum substrate concentration. Finally, for single substrate concentration assays, we argued for the use of saturating substrate concentration, as naturally occurring substrates might compete with the fluorogenic analog at trace level. The amendment of a molecule mimicking natural substrates generated a significant inhibition of natural seawater phosphatases and proteases assayed with trace concentrations of fluorogenic substrate, while almost no inhibition occurred at higher concentrations. Those key points need to be addressed in order to assess enzymatic rates and allow inter-study comparison. 


\section{Introduction}

Extracellular enzymes are mostly produced by heterotrophic prokaryotes that hydrolyse polymeric organic matter into units smaller than 600 Dalton, transportable across their cell membranes (Payne 1980). Although they are the only entity capable to significantly affect both dissolved and particulate organic matter (Chrost 1990), other organisms can release extracellular enzymes as well. For instance, phytoplankton, phototrophic prokaryotes, metazoa and macroalgae are able to contribute to the pool of alkaline phosphatases (Hoppe 2003; Niell et al. 2003; Labry et al. 2005).

Microbial enzymes play a major role in the ocean: they initiate the mineralization of complex organic matter through the microbial loop, transforming both dissolved and particulate organic matter into living biomass, dissolved organic carbon or carbon dioxide. The activity and specificity of extracellular enzymes therefore affect global carbon and nutrient cycling, carbon flow through aquatic food web as well as carbon export to the deep ocean (Azam et al. 1983; Azam 1998; Bidle 2010). As hydrolysis is considered the limiting step of organic matter utilization, any factors affecting enzyme activity might affect the entire mineralization pathway. As such, enzymatic assays are widespread and degradation capacity has been investigated in relation to diverse factors, such as for instance: substrate composition and size, microbial community structure or environmental conditions (Azam et al. 1983; Chróst 1990; Kirchman 2008).

Measurements of enzyme activity are typically carried out using fluorogenic molecules consisting of a substrate moiety covalently linked to a fluorophore (or fluorochrome). Non-hydrolysed substrate has a low background fluorescence, while upon hydßolysis the fluorescence spectra of the released fluorophore is considerably modified, allowing its selective detection (Fig. 1). The most commonly used molecules include 4-Methylumbelliferone (MUF) linked to monosaccharides (glycosidase assays) or phosphate groups (phosphatase assays) and 7-Amino-4-methylcoumarin (MCA) linked to amino acids (protease assays) (Arnosti 2003; Hoppe 1983; Kirchman 2008). Enzymatic activity is determined by following the increase in fluorescence over time and using standards of known fluorophore concentration. Even though the use of simple substrate analogs suffers from limitations (Arnosti 2011; Steen et al. 2015), they have been widely used thanks to their sensitivity and ease of use (Chróst 1990). 

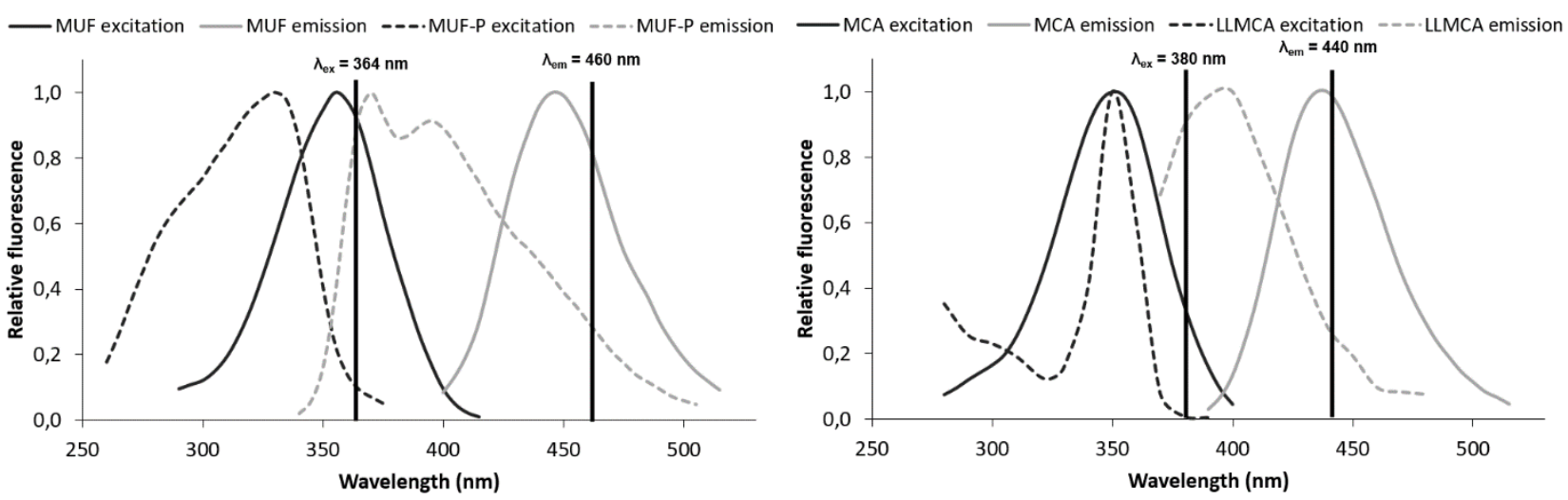

Fig. 1. (A) Normalized fluorescence spectra of MUF-P (alkaline phosphatase substrate, dashed lines) and MUF (product, solid lines) over emission (gray lines) or excitation wavelength (black lines). Excitation spectra of MUF and MUF-P were obtained using a constant emission wavelength $(460 \mathrm{~nm})$ while excitation wavelength varied. Emission spectra were obtained using a constant excitation wavelength (364 nm) with variable emission wavelength. (B) Normalized fluorescence spectra of LLMCA (protease substrate, dashed lines) and MCA (product, solid lines) over emission (gray lines) or excitation wavelength (black lines). To obtain excitation spectra of MCA and LLMCA, emitted light was respectively collected at a wavelength of 440 and $410 \mathrm{~nm}$ while excitation wavelength varied. To obtain emission spectra, emitted light was collected over a range of wavelength while excitation wavelength was set to 350 and $325 \mathrm{~nm}$ for MCA and LLMCA, respectively. em: emission, ex: excitation. Vertical lines represent excitation and emission wavelengths used during enzymatic assays.

However, several biases might affect result interpretation and impede inter-study comparison. The first one is a measurement artifact intrinsic to fluorimetry known as the Inner Filter Effect (IFE), which has been completely overlooked in the literature assaying enzymatic activity in environmental water samples. With conventional spectrofluorometers, a fluorescent molecule is excited by a light source at a specific wavelength, selected by a monochromator. The emitted fluorescence is collected at right angle with respect to the incident beam and detected by a photomultiplier at the emission wavelength, also selected by a monochromator (Valeur 2001). The IFE reduces the fluorescence signal due to the absorption of exciting (excitation IFE) or emitted light (emission IFE), which affects the relationship between fluorophore concentration and fluorescence intensity (Kao et al. 1998; Valeur 2001; Eccleston et al. 2005, see Fig. 2 for a conceptual representation). IFE can result from the fluorophore itself or any other light-attenuating molecules naturally present in the analysed sample. 


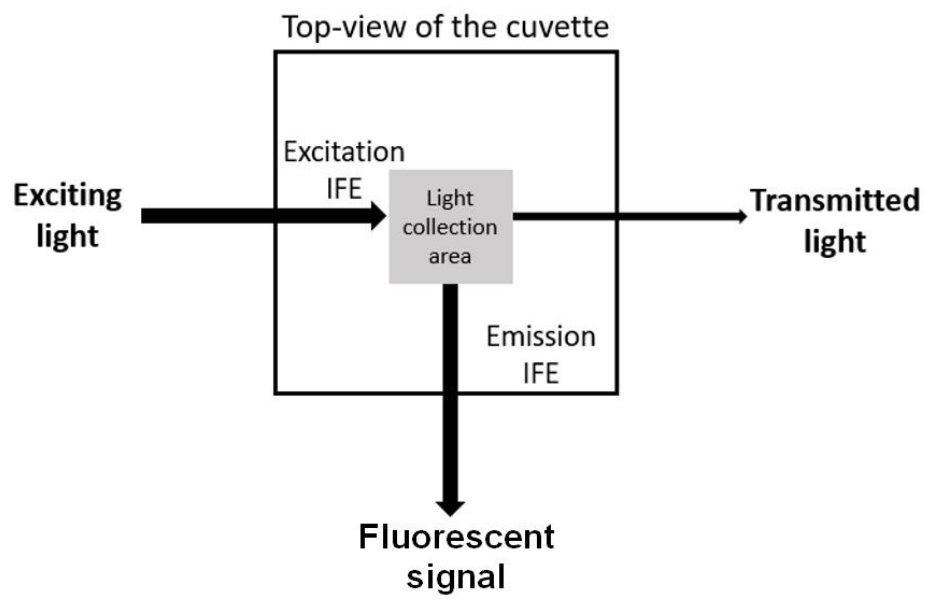

Fig. 2. Conceptual illustration of excitation IFE (also termed primary IFE) and emission IFE (also termed secondary IFE) using a right angle geometry, one of the most common for cuvette system.

The predominant effect, excitation or primary IFE, is caused by the absorption of the exciting light, which is attenuated as it progresses through the solution, inefficiently exciting the fluorophore. Absorption can be performed by the hydrolysis product, but also by the non-hydrolysed substrate. For instance, in the case of phosphatase assays, both MUF-Phosphate (MUF-P, alkaline phosphatase substrate) and MUF (hydrolysis product) absorb exciting light at the routinely used excitation wavelength $\left(\lambda_{\mathrm{ex}}=364 \mathrm{~nm}\right.$, Fig. 1). Substrate absorption seems minimal and is often completely neglected by investigators, but it can be significant in enzymatic assays performed with a high substrate to product ratio. Excitation IFE is favored by the use of concentrated solutions (absorbance > 0.1), which are almost inevitable in enzymatic assays (Valeur 2001; Eccleston et al. 2005). IFE is likely to occur with the conventional right angle geometry as detection system collects light on an area restricted to the center of the cuvette: light might be absorbed before even reaching the collection area (Kao et al. 1998; Valeur 2001). Different cell configurations, such as front face illumination, were specifically developed in order to avoid this and reduce IFE. Long optic path systems (i.e. $1 \mathrm{~cm}$ cuvette) are especially affected by IFE, although shorter optic path systems such as microtiter plate spectrofluorometers can be impacted as well (Pinto et al. 2015, Marathe et al. 2013). The age and efficiency of the exciting lamp can also play a role in the occurrence of this effect (Valeur 2001).

A secondary IFE might also arise if the emitted light is re-absorbed by surrounding molecules. Absorption by the fluorophore itself depends on its Stokes shift, which is the difference between 
emission and excitation maxima (Eccleston et al. 2005). A small Stokes shift implies that absorption and emission spectra strongly overlap, so the emitted light might be absorbed by non-excited fluorophore molecules, decreasing the measured signal. For molecules with large Stokes shift, such as MUF and MCA, emission IFE is not likely to occur (Fonin et al. 2014).

The IFE has been described before in biochemical studies using substrate analogs (Liu et al. 1999; Palmier and Van Doren 2007; Puchalski et al. 1991) but, to our knowledge, has never been considered in the context of marine studies. Sebastián and Niell (2004)reported a reduction of the reaction velocity by excess of substrate when assaying high substrate concentrations. . However, they did not mention a possible IFE.

The second bias is linked to the wide differences in substrate concentrations used, for both MichaelisMenten kinetics and single point assays. Before performing a single point enzymatic assay, kinetic parameters (maximum velocity $-\mathrm{V}_{\max }$ - and Michaelis affinity constant $-\mathrm{K}_{\mathrm{m}}$ ) should ideally be determined with a kinetic experiment using several substrate concentrations. However, there are wide differences in maximum substrate concentration used in the literature. They vary between 0.1 and 300 $\mu \mathrm{M}$ for alkaline phosphatase activities (APA) assayed with MUF-P (see Table 1 for references) and between 25 and $1000 \mu \mathrm{M}$ for exoproteolytic activities (EPA) assayed with L-Leucine-MCA (LLMCA, see Table 2 for references). Insufficient maximum substrate concentration can affect parameters determination as the saturation of enzymatic active sites might not be reached.

As kinetics are laborious, time consuming, expensive and require large sample volume, they are often set aside in favor of single point assays, using a single substrate concentration. A huge variability in the concentrations used is also noticed: between 0.1 and $250 \mu \mathrm{M}$ for APA assayed with MUF-P (see Table 1 for references) and between 2.5 and $1000 \mu \mathrm{M}$ for EPA assayed with LLMCA (see Table 2 for references). Those differences may be related to the existence of different perspectives in the current oceanographic community. Trace substrate concentration $(<1 \mu \mathrm{M})$ might be used in order to determine enzymatic rates and substrate turnover in conditions as close as possible to those prevailing in situ. This is opposed to a more conventional approach using a saturating substrate concentration, several times higher than the enzymes $\mathrm{K}_{\mathrm{m}}$ which allows the determination of maximal velocity rate (Chróst 1990; 
127 Hoppe 2003). Single point assays using low substrate concentration results in several issues. (i) The

128 substrate might not greatly exceed the enzyme concentration, which is a necessary condition to satisfy

129 the steady-state assumption made by Michaelis-Menten. (ii) Slow product formation leads to

130 fluorometric sensitivity issue (Chróst 1990). (iii) Those assays are subject to higher errors as velocities

131 correspond to the first order part of the Michaelis-Menten equation, which is the most variable region.

132 In consequence, small pipetting errors could result in large differences in estimated activity. (iv) At low

133 concentration, naturally occurring substrates might compete with the fluorogenic substrate analog,

134 leading to significantly underestimated activities (Chróst 1990). Consequently, measured activities

135 might be dependent on natural substrate concentration, potentially altering results and preventing intra

136 and inter-study comparison.

Table 1. Literature examples showing phosphatase activity assay conditions used in different environments. All

138 measurements were carried out using 4-Methylumbelliferyl phosphate (MUF-P) substrate.

139

\begin{tabular}{|c|c|c|c|c|}
\hline & Study & Environment & $\begin{array}{c}\text { Substrate range for } \\
\text { kinetic }(\mu \mathrm{M})\end{array}$ & $\begin{array}{c}\text { Substrate concentration for } \\
\text { single point assay }(\mu M)\end{array}$ \\
\hline \multirow{8}{*}{ 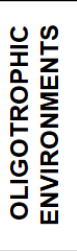 } & Sohm and Capone 2006 & Tropical and sub tropical north Atlantic & - & 0.1 \\
\hline & Sisma-Ventura and Rahav 2019 & Mediterranean Sea (microcosms) & - & 0.1 \\
\hline & Duhamel et al. 2014 & North pacific subtropical gyre & $0.025-1$ & 1 \\
\hline & Sala et al. 2001 & Mediterranean Sea & - & 200 \\
\hline & Van Wambeke et al. 2002 & Mediterranean sea & $0.025-1$ & - \\
\hline & Thingstad et al. 1998 & Mediterranean sea & $0.005-0.2$ & - \\
\hline & Yamaguchi et al. 2019 & Central north Pacific & $0.100-2$ & - \\
\hline & Bogé et al. 2012 & North west Mediterranean & $0.03-30$ & - \\
\hline \multirow{8}{*}{ 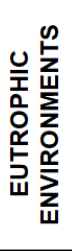 } & Rees et al. 2009 & English channel & - & 0.25 \\
\hline & Strojsova et al. 2008 & Eutrophic reservoir & - & 100 \\
\hline & Carlsson et al. 2012 & Coastal tropical Atlantic & - & 250 \\
\hline & Koch et al. 2009 & Coastal waters Florida bay & $0.05-2$ & - \\
\hline & Davis et al. 2014 & Celtic sea & $0.8-2$ & - \\
\hline & Chrost and Overbeck 1987 & Eutrophic Lake & $10-200$ & - \\
\hline & Labry et al. 2005 & Coastal estuarine waters & $0.5-250$ & 250 \\
\hline & Nausch et al. 2004 & Baltic sea & $0.1-300$ & - \\
\hline
\end{tabular}




\begin{tabular}{|c|c|c|c|c|}
\hline & Study & Environment & $\begin{array}{l}\text { Substrate range } \\
\text { for kinetic }(\mu \mathrm{M})\end{array}$ & $\begin{array}{c}\text { Substrate concentration for } \\
\text { single point assay }(\mu \mathrm{M})\end{array}$ \\
\hline \multirow{5}{*}{ 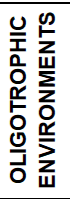 } & Van Wambeke et al. 2009 & Mediterranean Sea & $0.05-100$ & 50 \\
\hline & Talbot et al. 1997 & Strait of Magellan & - & 200 \\
\hline & Fukuda et al. 2000 & Subartic Pacific & - & 200 \\
\hline & Misic et al. 2002 & Antartica & $1-100$ & - \\
\hline & Caruso et al. 2019 & Mediterranean Sea & $20-160$ & - \\
\hline \multirow{12}{*}{ 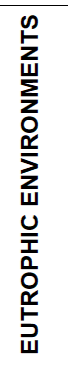 } & Gonnelli et al. 2013 & Arno river mouth (Italy) & $0.05-8.5$ & - \\
\hline & Song et al. 2019 & Brackish water microcosms & $0.1-20$ & - \\
\hline & Karner et al. 1992 & Adriatic Sea & - & 2.5 \\
\hline & Rath et al. 1993 & Caribbean Sea & $0.1-25$ & 2.5 \\
\hline & Chappell et al. 1995 & Ouse and Derwent Rivers (UK) & $0.5-100$ & 50 \\
\hline & Foreman et al. 1998 & Maumee River (USA) & - & 120 \\
\hline & Bullock et al. 2017 & Neuse and Tar-Pamlico Rivers (USA) & - & 400 \\
\hline & Cunha et al. 2001 & Estuarine ecosystem (Portugal) & - & 1000 \\
\hline & Patel et al. 2000 & Semi-enclosed coastal ecosystem & $2.5-40$ & - \\
\hline & Sinsabaugh et al. 1997 & Ottawa, Maumee and Hudson Rivers (USA) & $5-120$ & - \\
\hline & Shi et al. 2019 & Coastal waters, Northern South China Sea & $1-350$ & - \\
\hline & Ory et al. 2011 & Charente River (France) & $2-1000$ & - \\
\hline
\end{tabular}

143 The accumulation of these experimental biases might lead to severely misestimated enzymatic activities.

144 The purpose of this study is to address these issues by quantifying their effect on fluorometric enzymatic

145 assays. First, we will show how to detect the IFE occurrence, its effect on enzymatic measurements and

146 how it can be corrected. Secondly, we will address the effect of the substrate concentration ranges upon

147 the determination of kinetic parameters of pure enzymes, phytoplankton cultures and natural bacterial

148 communities. We will finally argue in favor of using saturating substrate concentrations when

149 performing single point assays, which allows the determination of the enzymatic equipment of the cells,

150 rather than the in situ degradation rate. 


\section{Reagents and solutions}

All chemical products were purchased from Sigma-Aldrich.

Substrate solutions. Stock solutions of $10 \mathrm{mM}$ 4-Methylumbelliferyl-phosphate (MUF-P) and $40 \mathrm{mM}$

L-Leucine-7-amido-4-methylcoumarin (LLMCA) were prepared in half a volume of 2-methoxyethanol, dissolved using sonication and volume was adjusted to final concentration with Milli-Q water (Millipore purification system). Working solutions from 0.5 to $500 \mu \mathrm{M}$ for MUF-P and from 3.9 to $1000 \mu \mathrm{M}$ for LLMCA were obtained by successive dilutions of stock solutions in Milli-Q water and stored at - 20 ${ }^{\circ} \mathrm{C}$.

Product solutions. Stock solutions of $2 \mathrm{mM}$ 4-Methylumbelliferone (MUF) and $4 \mathrm{mM}$ 7-Amino-4methylcoumarin (MCA) were prepared as described previously and used to prepare standards, as described in the following section.

Competitors for inhibition tests. Stock solutions of $4.2 \mathrm{mM}$ Glucose-6-phosphate (G6P), $10 \mathrm{mM}$ Leucyl-glycine (Leu-gly), $10 \mathrm{mM}$ L-Leucyl-glycyl-glycine (Leu-gly-gly) and $10 \mathrm{mM}$ Hexaglycine (Hexagly) were made in Milli-Q water, serially diluted to appropriate concentrations and stored at - 20 ${ }^{\circ} \mathrm{C}$.

\section{IFE detection}

Standards preparation. As non-hydrolysed substrate may affect fluorescence measurement, calibration curves of each product (MUF and MCA) were prepared in various concentration of substrate (MUF-P and LLMCA, respectively). Substrate concentrations are the ones used when determining enzymatic parameters. In practice, standards of MUF ranging from $8 \mathrm{nM}$ to $2 \mu \mathrm{M}$ were prepared in Milli-Q water or MUF-P concentration ranging from 0.5 to $500 \mu \mathrm{M}$, resulting in 12 calibrations for APA. Buffered formaldehyde (18\%, $\mathrm{pH} 8)$ was added to each standard to respect assay dilution conditions (3.3\% final concentration), as formaldehyde was used here to stop APA (C. Labry unpubl.). Standards of MCA ranging from $20 \mathrm{nM}$ to $2 \mu \mathrm{M}$ were prepared in Milli-Q water and in LLMCA concentration ranging from 3.9 to $500 \mu \mathrm{M}$ resulting in 9 calibrations for EPA. $10 \%$ sodium dodecyl 
sulfate (SDS) was added to each standard to respect assay dilution conditions (1\% final) as it is used to stop EPA. This is particularly important for EPA as $1 \%$ SDS was shown to result in a $20 \%$ increase in MCA fluorescence (Delmas and Garet 1995). All standards were stored at $-20^{\circ} \mathrm{C}$.

Fluorometric measurements. In this study, we compared classical cuvette readings with Flow Injection Analysis (FIA) reading (Delmas et al. 1994). Briefly, FIA is a liquid chromatography injection system (without the chromatographic column), connected to a Kontron SFM25 fluorescence spectrometer with a $1 \mathrm{~mm}$ optic path. This system allows a quick, sensitive and reproducible sample processing (Delmas et al. 1994). The use of a carrier fluid (here a $0.1 \mathrm{M}$ buffered borate solution adjusted to $\mathrm{pH} 10.5$ and delivered at $1 \mathrm{~mL} \mathrm{~min}^{-1}$ ) provides the possibility of setting the $\mathrm{pH}$ during fluorescence reading, independently from the $\mathrm{pH}$ of incubation. This is important as MUF fluorescence yield greatly varies with $\mathrm{pH}$ and is maximum at $\mathrm{pH}>10$ (Chróst and Krambeck 1986). For cuvette readings, pH was adjusted to 10 by adding 0.98 and $0.20 \mathrm{~mL}$ of a $0.5 \mathrm{M} \mathrm{pH} 12$ buffered borate solution per $4 \mathrm{~mL}$ sample (containing preservative) for APA and EPA respectively. Measurements were carried out in a $1 \mathrm{~cm}$ cuvette using two spectrofluorometers, SFM25 and Perkin Elmer LS50.

All measurements were performed with a $90^{\circ}$ angle illumination. Excitation and emission wavelength were respectively $364 \mathrm{~nm}$ and $460 \mathrm{~nm}$ for APA and $380 \mathrm{~nm}$ and $440 \mathrm{~nm}$ for EPA.

\section{Michaelis-Menten kinetics}

Michaelis-Menten kinetics were carried out on various samples to evaluate the impact of IFE and of substrate concentration ranges on kinetic parameters determination.

Sample preparation. Tested samples were either purified enzymes, phytoplankton cultures or natural microbial communities. Purified enzymes from Escherichia coli and shrimp (acquired from Sigma/Aldrich) were diluted to a stock concentration of $10 \mathrm{mU} \mathrm{mL}^{-1}$ in Milli-Q water and stored at 4

${ }^{\circ} \mathrm{C}$. For each activity assay, stock enzyme was diluted to $250 \mu \mathrm{U} \mathrm{mL}^{-1}$ in $0.2 \mu \mathrm{m}$ filtered natural seawater (Whatman Nucleopore filters).

Alexandrium minutum and Thalassiosira weissflogii were precultured in F/4 medium (Guillard and Ryther 1962) and inoculated in phosphate-free $\mathrm{F} / 4$ medium for 3 days at $18^{\circ} \mathrm{C}$, under a $12: 12$ light cycle 
(120 $\mu$ mol photons $\left.\mathrm{m}^{-2} \mathrm{~s}^{-1}\right)$. Activities were measured on total fraction comprising algal-attached and dissolved enzymes.

Natural seawater was collected from the Brest station of the Service d'Observation en Milieu LITtoral program (SOMLIT, French marine monitoring network, http://somlit.epoc.u-bordeaux1.fr). and filtered through $0.8 \mu \mathrm{m}$ Whatman Nucleopore filters to remove eukaryotes and larger cells.

Incubations. In order to determine kinetic parameters, $2 \mathrm{~mL}$ samples were incubated in the dark with $50 \mu \mathrm{L}$ substrate solutions, with final concentrations ranging from 0.5 to $500 \mu \mathrm{M}$ for MUF-P and from 1.95 to $1000 \mu \mathrm{M}$ for LLMCA). Incubation time for each type of sample was previously determined so that less than $25 \%$ of the substrate was hydrolysed, in order to measure initial linear velocity. Natural bacterial communities were incubated at in situ temperature (between 12 and $16^{\circ} \mathrm{C}$ ), purified enzymes and phytoplankton cultures at $20^{\circ} \mathrm{C}$. At the end of the incubation, reaction was stopped by adding $18 \%$ buffered formaldehyde ( $\mathrm{pH} 8,3.3 \%$ final concentration) for APA or 10\% SDS for EPA (1\% final concentration). Samples were then frozen at $-20{ }^{\circ} \mathrm{C}$ until fluorescence measurement, which was performed as previously described. These preservatives stop enzymatic activities and allow storage at -

$21720^{\circ} \mathrm{C}$ for deferred sample analysis, if necessary, without any changes on the kinetic parameters (APA: C. Labry unpubl., EPA: Delmas and Garet 1995).

Controls. As natural seawater and substrates (MUF-P and LLMCA) do produce fluorescence, a blank sample was prepared for each substrate concentration by directly mixing samples, substrate and reaction inhibitor (formaldehyde for APA, SDS for EPA) and immediately freezing them at $-20{ }^{\circ} \mathrm{C}$. Blank fluorescence was then subtracted from sample fluorescence and results were converted to degradation rates using product standards diluted in Milli-Q water.

Statistical analysis. Affinity constant $\left(\mathrm{K}_{\mathrm{m}}\right)$ and maximum velocity $\left(\mathrm{V}_{\max }\right)$ and their standard deviations were calculated using nonlinear least squares regression of the data fitted to the Michaelis-Menten equation, using R ("nls" function in the "stats" package). Non-linear regression seems to be the best method to estimate kinetic parameters (Chróst 1990). 


\section{Inhibition tests}

229 To assess the effect of natural competitors on APA and EPA of natural bacterial samples, we monitored 230 the fluorescence emitted by $3 \mathrm{~mL}$ seawater sample amended with $75 \mu \mathrm{L}$ substrate $(0.125$ to $2 \mu \mathrm{M}$ of 231 MUF-P, 0.125 and $2 \mu \mathrm{M}$ of LLMCA) in a $1 \mathrm{~cm}$ optic path cuvette (SFM25 spectrofluorometer) during 232 short periods of time (2 to $10 \mathrm{~min}$ ). A molecule competing with the substrate analog was then added and 233 fluorescence was monitored using the same procedure. The competitor used for APA was G6P (75 $\mu \mathrm{L}$, 234 final concentration from $50 \mathrm{nM}$ to $1.5 \mu \mathrm{M}$ ), a natural compound involved in bacterial metabolism which 235 is susceptible to be present in both natural environments and cultures. For EPA, three competitors were 236 tested: Leu-gly, Leu-gly-gly and Hexagly (30 $\mu \mathrm{L}$, final concentration of 8 and $16 \mu \mathrm{M})$. Fluorescence 237 increased linearly over time and the presence of competitors visibly affected the slopes, which 238 correspond to reaction velocities. $\mathrm{pH}$ was not adjusted during this measurement as slopes were not 239 converted to actual velocities. Slopes were corrected for the dilution due to competitor's addition. 


\section{Assessment and discussion}

\section{Influence of IFE on activity assays}

242 IFE occurs when exciting or emitted light is absorbed, decreasing the fluorescence signal and resulting in underestimated enzymatic activities. It includes all light-attenuating processes, caused by the

244 fluorogenic substrate analog itself or by any other chromophores naturally present in samples. This study is limited to IFE caused by fluorogenic substrate as it is important during enzymatic assays using large concentration of substrate, but IFE resulting from natural organic matter may also affect fluorometric assays (Kothawala et al. 2013). IFE resulting from natural compounds should theoretically be corrected using calibration curves prepared in the same matrix as the samples (for instance $0.2 \mu \mathrm{m}$ filtered seawater).

\section{Detection of IFE caused by fluorogenic substrate}

MUF-P/MUF and LLMCA/MCA have similar excitation and emission spectra, characterized by a large Stokes shift, meaning that emission IFE should not occur. However, both non-hydrolysed substrates and hydrolysis products can absorb exciting light and produce an excitation IFE.

The occurrence of an excitation IFE from fluorescent products was tested by measuring calibration standards of products (MUF and MCA) diluted in Milli-Q water. If this effect occurs, the released product will absorb exciting light, with a greater impact at high product concentration. Consequently, the emitted signal will not be linear over the product range of concentration. As the curves obtained were linear (determination coefficient for linear fitting: $R^{2}>0.999$, data not shown) for the three instruments (FIA-SFM25, SFM25 and LS50), it appears that there is no IFE from the product between 0 and $2 \mu \mathrm{M}$, for both MUF and MCA.

Excitation IFE resulting from non-hydrolysed substrates can be detected by measuring fluorescence of the reaction product in varying substrate concentrations. If an IFE occurs, we expect that a given substrate concentration will affect the fluorescence of all product concentrations in a similar way. The linearity of the relationship between fluorescence and product concentration would be unaffected. However, the IFE would increase with increasing substrate concentration which would result in a reduction of the calibration slope. 
Figure 3 shows the results obtained for APA (no IFE detected, Fig. 3a, c, e) and EPA (IFE detected,

Fig. 3b, d, f) with LS50 spectrofluorometer. Without IFE, the slope of those calibration curves is independent from MUF-P concentration (slope $=-6.77 \times 10^{-6}$, correlation coefficient $r=0.236, d f=10$, not significant, Fig. 3c) as MUF-P substrate does not affect fluorescence reading. The intercept is linearly proportional to this concentration (slope $=0.25, r=1.000, d f=10$, significant at $0.1 \%$, Fig. 3e), reflecting the natural fluorescence of the substrate. These results also show the necessity of using a blank for each substrate concentration assayed. When an IFE occurred, the slope of the calibration curves decreases with increasing LLMCA concentration (slope $=-4.37 \times 10^{-5}, r=0.742, d f=8$, significant at 5\%, Fig. 3d): as exciting light is absorbed, it becomes limiting and the fluorochrome is not fully excited. As expected, this effect is more pronounced at higher concentration of LLMCA, affecting calibration curve slopes in a greater manner. For similar reasons, the intercept does not vary linearly at high LLMCA concentrations (Fig. 3f).

Overall, no IFE was detected when assaying APA with all three tested instruments. An IFE was detected for proteases assays performed using cuvettes (SFM25 and LS50) but not using FIA-SMF25. The absence of IFE using FIA-SFM25, compared to the cuvette systems, might be due to both the sample dilution by hydraulic system (as sample is diluted about 10 times by carrier fluid) and by the 10 times shorter optic path, resulting in 100 times less substrate interfering with light flux. A greater overlap of fluorescence spectra, as well as different samples dilution (see following discussion), might favor the occurrence of IFE with the EPA assays compared to the APA assays.. Those results illustrate the fact that this effect greatly depends on the type of substrate, concentrations and equipment used and should be regularly tested for each assay protocol. 
a.

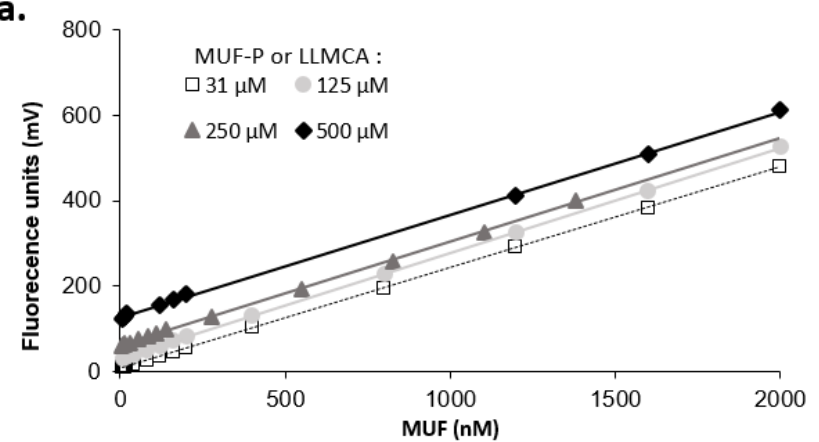

c.

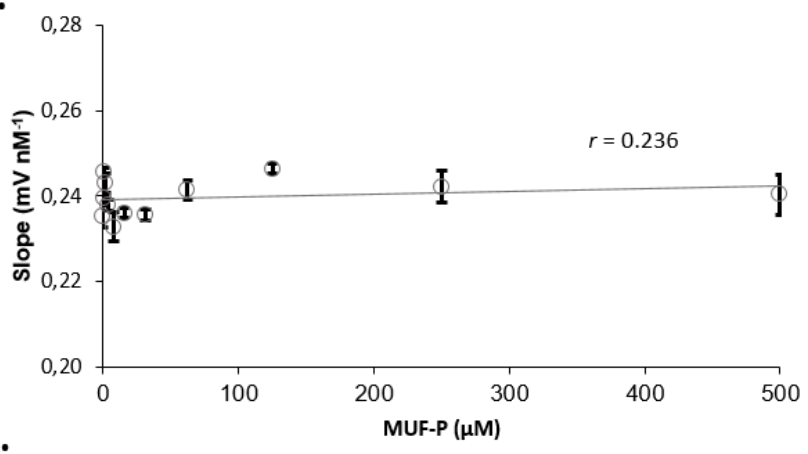

e.

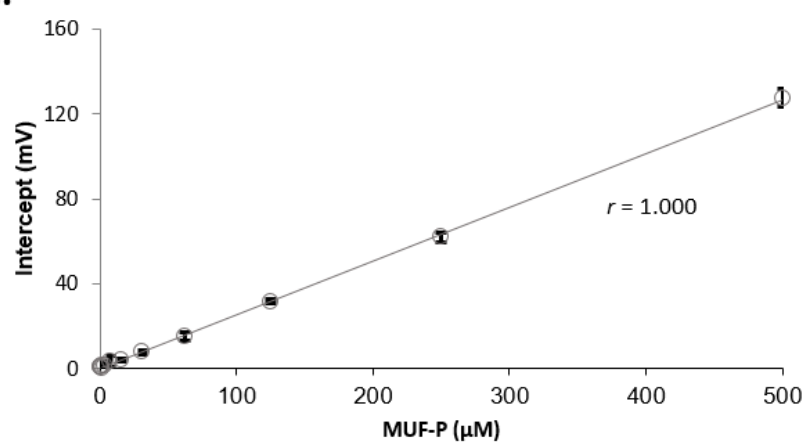

b.

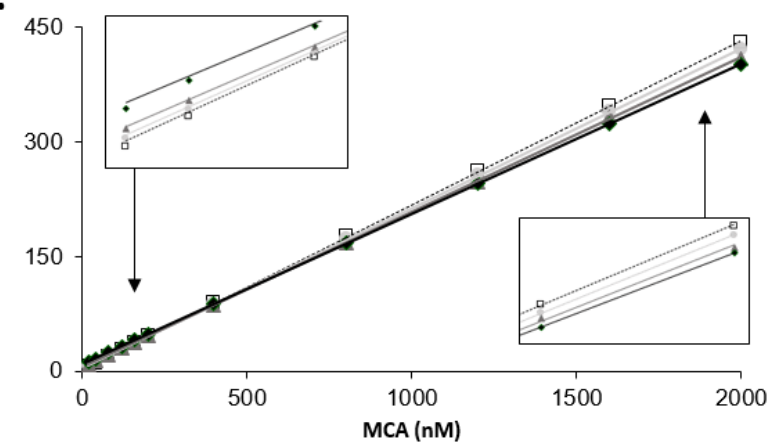

d.

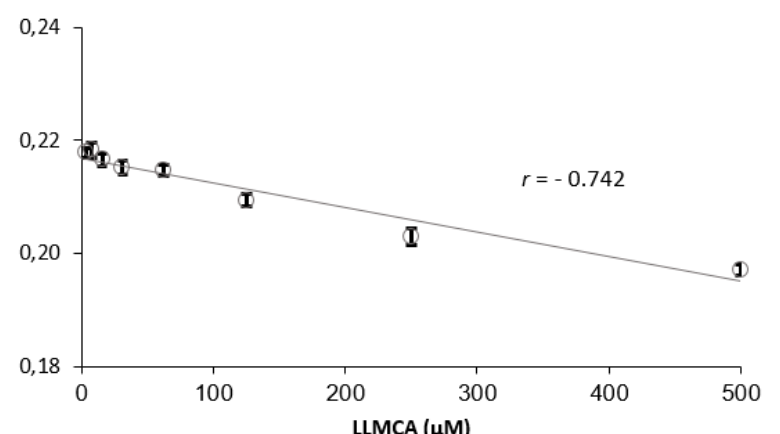

f.

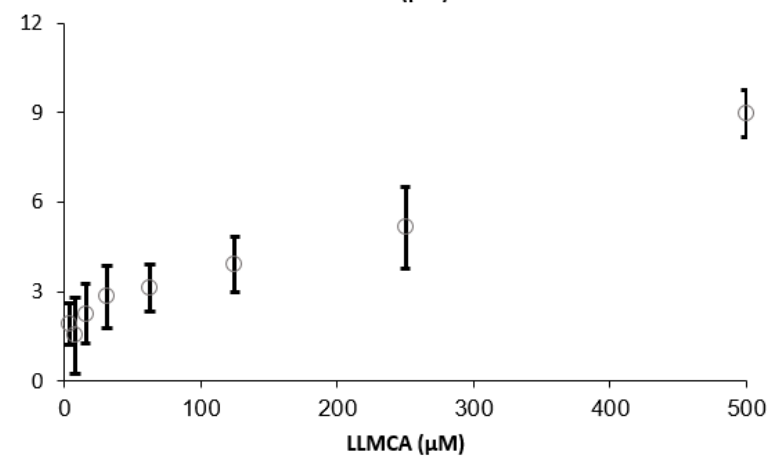

Fig. 3. Detection of IFE using calibration curves of MUF (a, $c, e)$ and MCA $(b, d, f)$, with cuvette operated LS50 spectrofluorometer. Calibration curves $(a, b)$ were determined from solutions prepared in varying concentration of nonhydrolysed substrate (MUF-P, LLMCA). On panel a and b, only four calibration curves are shown to facilitate readability although 12 and 9 curves were respectively measured for APA and EPA. All calibrations are displayed on other panels. Calibration of MUF shows no IFE as the slope of each calibration is not dependent on MUF-P concentration (c) and intercept varies linearly with MUF-P concentration (e). Calibration of MCA exhibits an IFE as the slope of each calibration varies significantly with LLMCA concentration (d) and intercept does not vary linearly above $60 \mu M$ of LLMCA (f). $r$ : correlation coefficient. Error bars (c, $d, e, f)$ represent $95 \%$ confidence interval of the fitted parameters.

\section{Consequences and correction of IFE}

298 To assess the consequences of the detected IFE on natural samples, we carried out a kinetic measurement of natural bacterial communities EPA. The samples were measured using both FIA-SFM25 and cuvette operated LS50 with pH correction. 
With FIA-SFM25, unweighted hyperbolic regression gave a $V_{\max }$ of $3386 \pm 198 \mathrm{nM} \mathrm{h}^{-1}$ and a $\mathrm{K}_{\mathrm{m}}$ of $275 \pm 40 \mu \mathrm{M}$. When carried out with LS50 for which IFE occurs, $\mathrm{V}_{\max }$ only reached $2668 \pm 154 \mathrm{nM}$ $\mathrm{h}^{-1}$ and $\mathrm{K}_{\mathrm{m}}$ equalled $205 \pm 32 \mu \mathrm{M}$, hence a respective difference of 21 and $26 \%$ on each parameter (Fig.
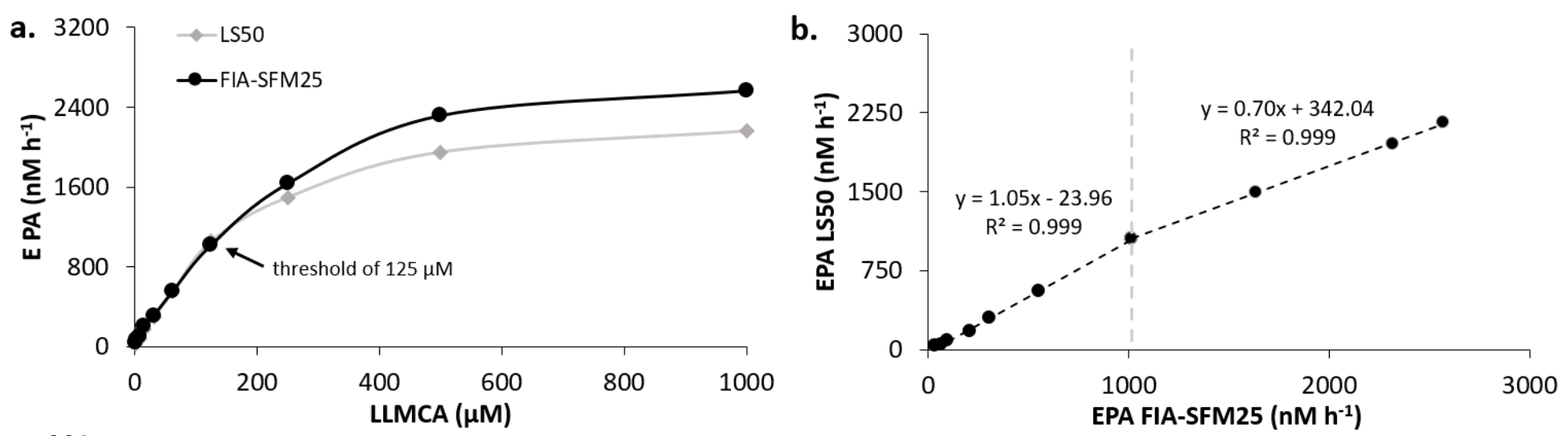

Fig. 4. (a) Kinetics of natural bacterial communities EPA measured using FIA-SFM25 (black line) or with LS50 (using cuvette, grey line). (b) Correlation between EPA measured with LS50 (using cuvette) and using FIA-SFM25. Dashed line highlights the substrate concentration threshold.

This threshold value is close to the $150 \mu \mathrm{M}$ self-quenching threshold observed by Saifuku et al. (1978) in the original method of LLMCA assay.

314 IFE can be avoided by using diluted solutions, shorter optic path, horizontal over vertical slits, a change 315 in lamp geometry or in excitation/emission wavelengths (Valeur 2001; Eccleston et al. 2005; Fonin et al. 2014). However, it is not always possible to modify those parameters and this effect cannot always

317 be avoided. In such cases, it should be corrected either experimentally or mathematically. If mathematic 318 corrections are available, they can be quite complicated to implement (see Fonin et al. 2014 or Puchalski et al. 1991 for references). To experimentally correct the IFE in a simple way, each fluorescence value obtained with a given substrate concentration was converted into a concentration using the calibration 
curve prepared in Milli-Q water. For instance, the values measured when assaying EPA with $1000 \mu \mathrm{M}$ of LLMCA were converted using the MCA standards prepared in $1000 \mu \mathrm{M}$ of LLMCA. The corrected values with LS50 are: $V_{\max }=3267 \pm 183 \mathrm{nM} \mathrm{h}^{-1}$ and $\mathrm{K}_{\mathrm{m}}=288 \pm 40 \mu \mathrm{M}$, hence a respective difference of 4 and 5\% on each parameter, which is within standard error inherent to fluorometric measurement and model fitting.

\section{Importance of protocol and equipment used}

We would like to draw specific attention to the fact that IFE greatly depends on protocol as well as equipment used.

The first methodological key point would be the preparation of calibration curves, which are necessary to correctly assess and correct IFE. As this effect is dependent on dilution, calibration solutions should be prepared in the exact same manner as the samples. In our protocol, all samples were diluted 1.2 times by the preservative (formaldehyde or SDS), which was consequently also added to the standards. Preservative is, to our knowledge, almost never amended in calibration solutions.

The second methodological key point concerns the $\mathrm{pH}$ adjustment when fluorescence is measured using cuvette. Our samples were further diluted by buffered borate amendment (1.24 times for APA, 1.05 times for EPA) to adjust $\mathrm{pH}$ to 10 , which maximizes MUF and MCA fluorescence and allows the comparison between FIA and cuvette measurements. As such, IFE is minimized in our protocol. This is especially true for APA, for which larger volumes of buffer were necessary to reach $\mathrm{pH}=10$. However, in the literature, it is often unclear if $\mathrm{pH}$ adjustment is performed when using cuvettes or microplates. If not, IFE could be much more severe.

Another methodological key point would be the choice of excitation wavelength. For instance, Christie et al. (1978) noted that an excitation wavelength of $350 \mathrm{~nm}$ was necessary to overcome an IFE that was observed at $320 \mathrm{~nm}$ (maximum excitation wavelength) with MUF- $\alpha$-D-mannopyranoside and MUF- $\alpha$-D-glucopyranoside with a spectrofluorometer using cuvette. This is especially important for MCA as an excitation wavelength of $360 \mathrm{~nm}$ (maximum of excitation) will favor IFE due to a bigger absorbance by LLMCA (Fig. 1).

The occurrence of IFE strongly depends on the equipment used. For instance, Briciu-burghina et al. (2015) encountered a pronounced IFE in $1 \mathrm{~cm}$ optic path cuvette using MUF- $\beta$-D-glucuronide substrate, 
whose fluorescence spectra resemble MUF-P spectra, for which we found no IFE. This could be due,

for example, to differences in cell geometry, slits orientation, fluorescence observation angle, lamp power and age (Valeur 2001; Eccleston et al. 2005; Fonin et al. 2014).

Microplate spectrofluorometer have been increasingly used as they allow high throughput assays and limit the substrate volume, although the small incubation volume and long incubation time may lead to bottle wall-effects (higher enzyme and substrate adsorption). IFE seems less likely to occur with those set-ups thanks to front-face optics and small optic path. However, studies using 96-wells microplates have shown its occurrence with MUF derivative substrates. For instance, Pinto et al. (2015) reported an IFE using MUF-galactoside, without specifying the importance of the effect. Marathe et al. (2013) found an IFE using 2'-(4-methylumbelliferyl)- $\alpha$-D-N-acetylneuraminic acid, which was an important interference in their assay. Even though microplates are less prone to IFE, its occurrence should be checked in every spectrofluorometer.

\section{Influence of substrate concentration range on kinetic parameters determination}

To illustrate the effect of substrate concentration range on kinetic parameters determination, we conducted APA measurements on purified enzymes (E. coli and shrimp), phytoplankton cultures ( $A$. minutum and $T$. weissflogii) and natural bacterial populations. Several fittings were consecutively made on each kinetics to determine $\mathrm{V}^{\mathrm{n}}{ }_{\max }$ and $\mathrm{K}^{\mathrm{n}}{ }_{\mathrm{m}}$ each time eliminating the highest concentration of substrate $\left(\mathrm{S}_{\max }\right)$. This process aims to illustrate the impact of substrate concentration range by decreasing the maximum concentration used from $S_{\max }=500 \mu \mathrm{M}$ ( $n=11$ points) to $S_{\max }=2 \mu \mathrm{M}(n=3)$. The resulting variation of parameters is due to fitting artifact. It should be noted that only an apparent $\mathrm{K}_{\mathrm{m}}$ can be determined, as natural substrates might be present in the medium, competing with the substrate analog.

Figure 5 shows the results obtained for the purified E. coli APA. Both $\mathrm{V}^{\mathrm{n}}$ max and $\mathrm{K}_{\mathrm{m}}$ increase (respectively $+61 \%$ and $+157 \%$ ) when $S_{\max }$ increases from $2 \mu \mathrm{M}$ to $60 \mu \mathrm{M}$. Both parameters then tend to plateau at higher $S_{\max }$, reaching what can be considered as their "true" value when $S_{\max }=500 \mu \mathrm{M}$ $\left(\mathrm{V}_{\max }^{\mathrm{t}}=952 \mathrm{nM} \mathrm{h}^{-1}\right.$ and $\left.\mathrm{K}_{\mathrm{m}}^{\mathrm{t}}=6.5 \mu \mathrm{M}\right)$, even though $\mathrm{K}_{\mathrm{m}}^{\mathrm{n}}$ still seems to vary consequently. The threshold concentration of $60 \mu \mathrm{M}$ roughly corresponds to $10 \mathrm{~K}_{\mathrm{m}}^{\mathrm{t}}$. This value is generally recommended as a 

sites are occupied, as dealing with concentrated solutions can be complicated (Bisswanger 2014) .

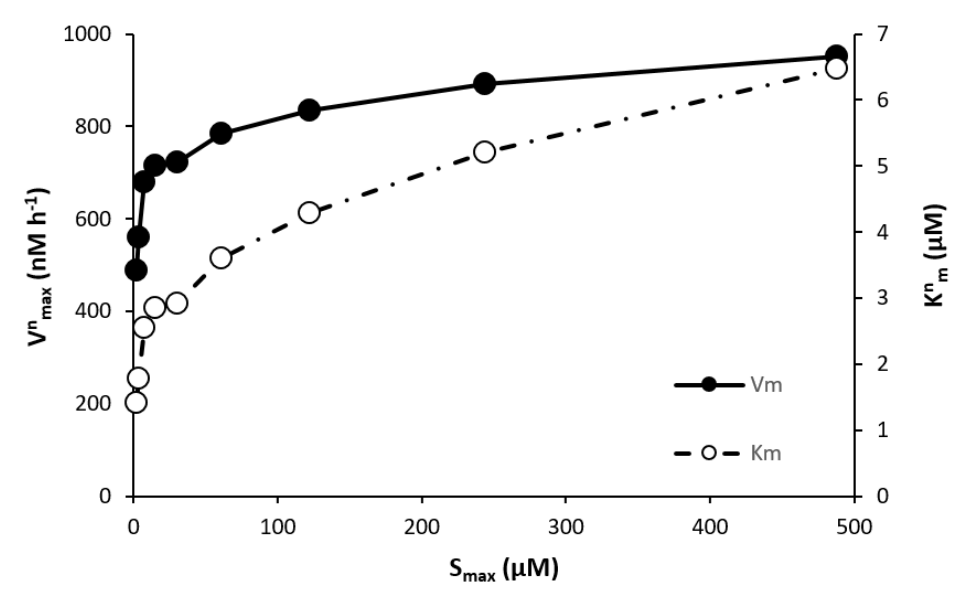

Fig. 5. Evolution of kinetic parameters $\left(V^{n}{ }_{\max }, K^{n}{ }_{m}\right)$ of purified E. coli alkaline phosphatase over the maximum substrate concentration ( $\left.S_{\max }\right)$ used. Several fittings were done on the same assay data, iteratively removing the highest substrate concentration. Correlation coefficient indicated significant results for $n>4$ (at $0.1 \%)$.

In order to compare the results of consecutive fittings performed on different enzymes, kinetic parameters $\left(\mathrm{V}^{\mathrm{n}}{ }_{\max }\right.$ and $\left.\mathrm{K}_{\mathrm{m}}^{\mathrm{n}}\right)$ were normalized by the "true" kinetic parameters $\left(\mathrm{V}^{\mathrm{t}}{ }_{\max }\right.$ and $\left.\mathrm{K}_{\mathrm{m}}^{\mathrm{t}}\right)$ determined using the largest substrate concentration range $\left(S_{\max }=500 \mu \mathrm{M}\right)$. Figure 6 presents the normalized velocities $\left(\mathrm{V}^{\mathrm{n}}{ }_{\max } / \mathrm{V}_{\text {max }}^{\mathrm{t}}\right)$ plotted against the normalized maximum substrate concentration $\left(\mathrm{S}_{\max } / \mathrm{K}_{\mathrm{m}}^{\mathrm{t}}\right)$, which allows to observe the impact of $S_{\max }$ independently from the enzyme's affinity. It clearly shows the same pattern as before: $\mathrm{V}^{\mathrm{n}}$ max greatly varies with low $\mathrm{S}_{\max }$, then tends to stabilize around the correct parameter estimation at higher $\mathrm{S}_{\max }\left(>25 \mathrm{~K}_{\mathrm{m}}^{\mathrm{t}}\right.$ ). Normalized $\mathrm{K}_{\mathrm{m}}$ follows the exact same pattern (data not shown). 


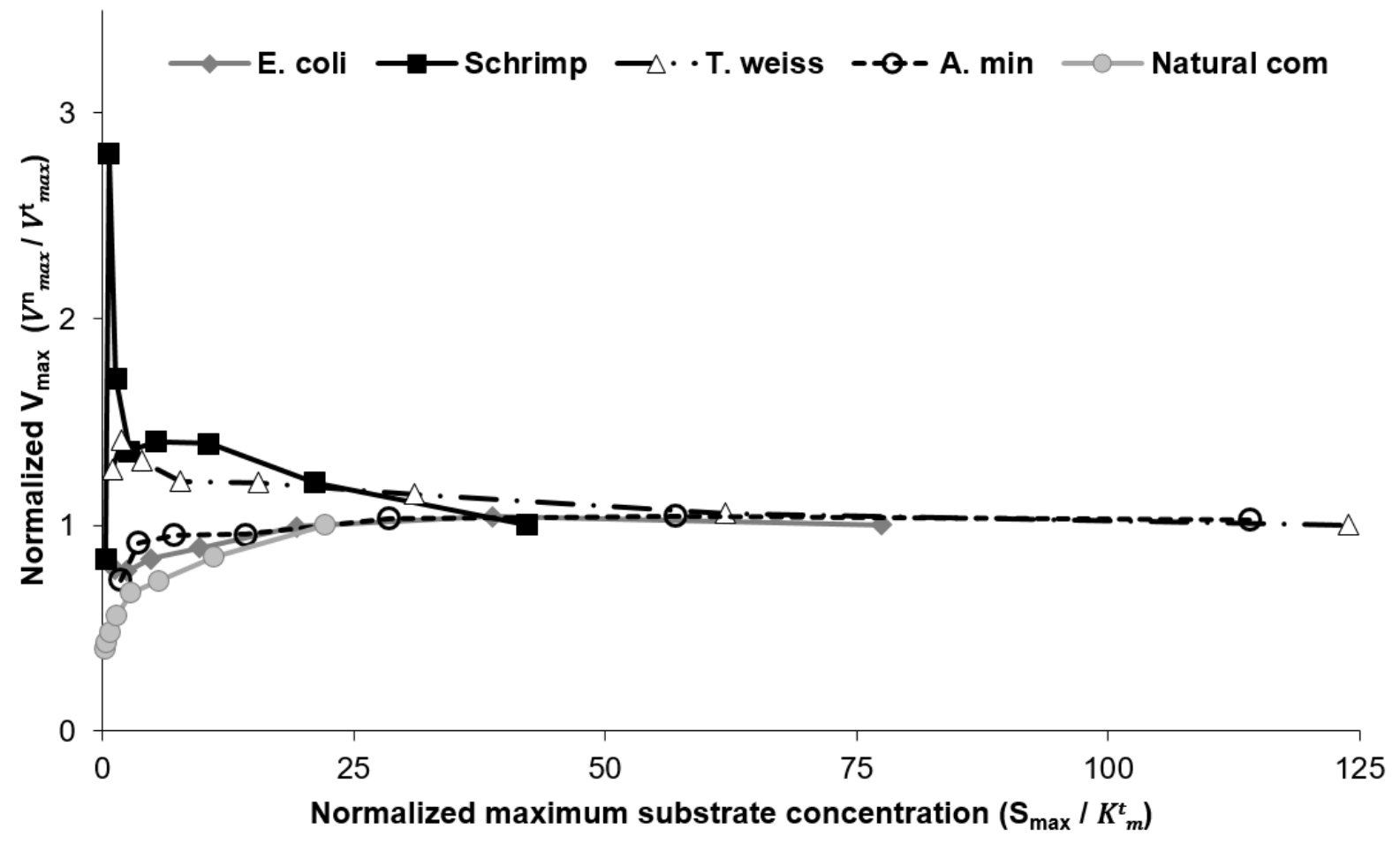

Fig. 6. Normalized $V_{\max }\left(V^{n}{ }_{\max } / V_{\max }^{t}\right)$ over normalized maximum substrate concentration $\left(\mathrm{S}_{\max } / K^{t}{ }_{m}\right)$ of APA assays conducted on various samples (purified enzymes from shrimp and E. coli, cultures of T. weissflogii and A. minutum and natural bacterial communities). Each dot represent a non-linear fitting done on the same kinetic experiment data, but iteratively reducing $S_{\text {max }}$ which is represented normalized on the X-axis. Velocities are normalized by the "true" $V_{\max }^{{ }}$obtained at $S_{\max }=500 \mu M$ and substrate concentrations are normalized by the "true" $K_{m}^{t}$ obtained at $S_{\max }=500 \mu M$.

This experiment illustrates the consequences of the use of insufficient $S_{\max }$ to determine kinetic parameters. Both low and high substrate concentration are necessary to correctly fit all parts of the Michaelis-Menten equation ( 0 and $1^{\text {st }}$ order, Chróst 1990). The width of the range depends on the enzyme affinity, since enzymes with low $\mathrm{K}_{\mathrm{m}}$ are easily saturated and the curve's plateau will be reached even at low $S_{\max }$. High affinity enzymes (low $K_{m}$ ) are usually thought to occur in oligotrophic environments since they are supposed to process substrates at very low concentrations (Chróst 1991; Rath et al. 1993). However, even in those environments, $S_{\max }$ should be carefully chosen. For instance, all five studies determining enzymatic parameters in oligotrophic environments listed in Table 1 contained at least one experiment where $\mathrm{K}_{\mathrm{m}}$ was equal or greater than $\mathrm{S}_{\max }$. In contrast, enzymes are considered to have lower substrate affinity (high $\mathbf{K}_{\mathrm{m}}$ ) in eutrophic environments (Chróst 1991; Rath et al. 1993), so substrate ranges should be even wider. Similar results were obtained for EPA (not shown). 
As the variation of kinetic parameters results from a fitting artifact, it should logically occur for all enzymatic kinetics.

Effect of natural substrates competition at trace concentration of analog substrate

410 Substrate concentration used for single point assays varied from $0.1 \mu \mathrm{M}$ to $250 \mu \mathrm{M}$ for APA assayed with MUF-P (see Table 1 for references) and from 2.5 to $1000 \mu \mathrm{M}$ for EPA assayed with LLMCA (see

412 Table 2 for references). Low substrate concentrations are usually used in oligotrophic conditions, in 413 order to mimic mean environmental conditions. However, in such assays, naturally occurring substrates 414 might compete with the analog substrate. To illustrate this effect, we performed APA assays on natural seawater microbial communities using trace substrate concentrations of MUF-P $(0.125-2 \mu \mathrm{M}$, similar to those in studied literature) amended with different concentrations of G6P $(0.1-1.5 \mu \mathrm{M})$. G6P was arbitrarily chosen to mimic dissolved organic phosphorus (DOP), the natural substrate of phosphatases. Concentrations were chosen to be representative of DOP concentration in natural environments: it usually ranges from 0 to $0.2 \mu \mathrm{M}$ in open ocean surface waters (Ridal and Moore 1992; Karl and Björkman 2015) while coastal and estuarine waters often contain more than $0.25 \mu \mathrm{M}$ DOP (Karl and Björkman 2015; Labry et al. 2016), with values sometimes exceeding $2 \mu \mathrm{M}$ (Rinker and Powell 2006). Activities were measured as slopes of fluorescence over time (in $\mathrm{mV} \min ^{-1}$ ) and expressed as percentage of maximum activity, measured without inhibitors, for each substrate concentration (Fig. 7). With a MUF-P concentration of $0.125 \mu \mathrm{M}$, G6P concentrations of $0.1,0.2,0.6$ and $1.5 \mu \mathrm{M}$ decrease MUF-P hydrolysis by 11, 18, 22 and 38\%, respectively. Inhibition patterns are quite similar with 0.25 , and $0.5 \mu \mathrm{M}$ MUF-P, while those effects are lower at $1 \mu \mathrm{M}$ and tend to disappear at $2 \mu \mathrm{M}$ MUF-P (1-8\% reduction). As measurement are carried out in seawater, naturally occurring DOP is also competing for the enzymes' active sites, so the actual effect of G6P might be underestimated. However, results clearly show that competition depends on the ratio of competitor to MUF-P and is not susceptible to happen at saturating concentration of MUF-P. 


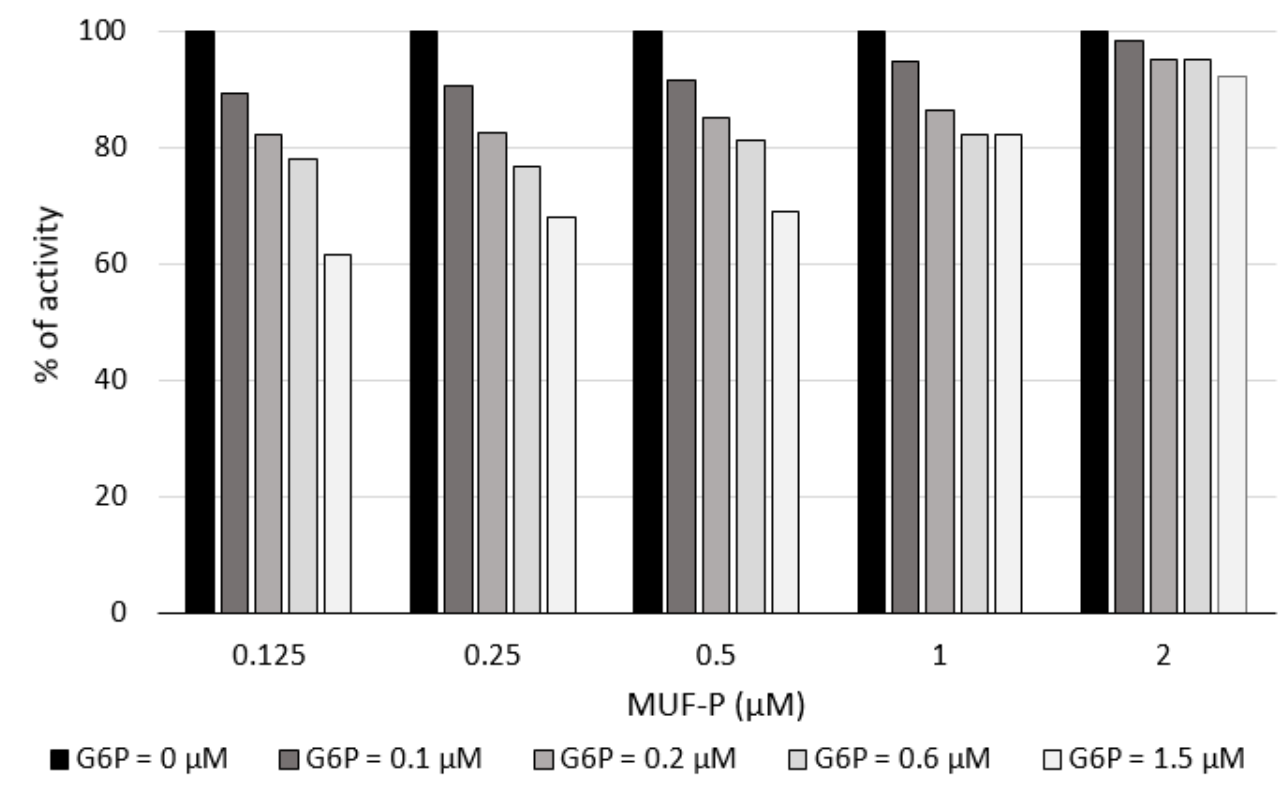

Fig. 7. APA measured using trace MUF-P concentrations with various concentrations of G6P, a natural non-fluorescent competitor. Results are given in $\mathrm{mV} \mathrm{min}^{-1}$ and normalized by the maximum activity obtained for each MUF-P concentration (without competitor).

Although G6P was used as a single competitor, samples often contain a mixture of compounds with their own affinity and inhibition constant, affecting enzymatic assays in different ways. The competitor's affinity for the enzyme (hence its effect on measurement) might especially vary for polymeric substances given their huge diversity (peptides or carbohydrates for example). We conducted similar tests on EPA, amending 8 and $16 \mu \mathrm{M}$ Leu-Gly, Leu-Gly-Gly or Hexagly to 0.125 and $2 \mu \mathrm{M}$ LLMCA. Although high, those competitor concentrations are representative of natural environments as combined dissolved amino acids may vary from 0.2 to $8 \mu \mathrm{M}$ in oligotrophic to coastal waters (Keil and Kirchman 1991). As a result, $8 \mu \mathrm{M}$ of Leu-Gly, Hexagly and Leu-Gly-Gly generated an inhibition of 18, 19 and 34\%, while $16 \mu \mathrm{M}$ generated respectively 25,33 and $41 \%$ of inhibition (Fig. $8 \mathrm{a}$ ). Those results might be explained by the fact that measurements using peptidase substrates actually represent the concerted action of many distinct enzymes, as suggested by Steen et al. (2015), who performed competition experiments between 12 amino acid-p-nitroanilide compounds and 3 fluorogenic substrates (LLMCA, L-arginine-MCA, Lproline-MCA). As expected, the use of higher concentration of LLMCA $(2 \mu \mathrm{M})$ reduced the inhibition: $8 \mu \mathrm{M}$ of Leu-GLy, Hexagly and Leu-Gly-Gly generated 5, 10 and 8\% inhibition respectively while 16 
a. $0.125 \mu \mathrm{M}$ LLMCA

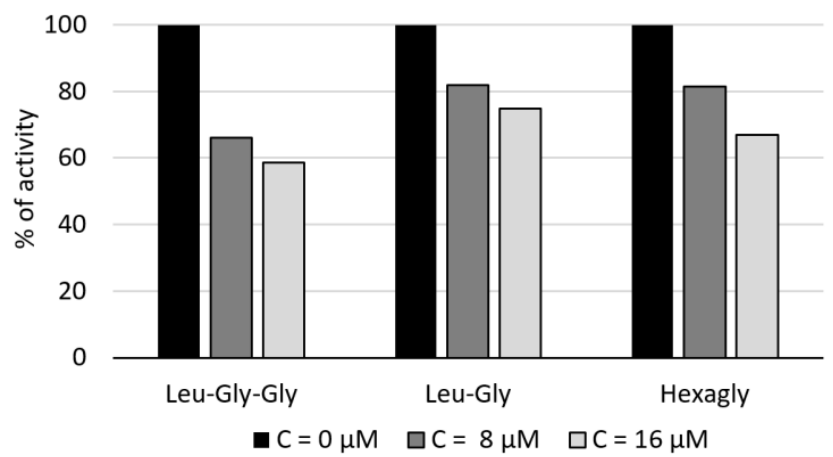

b. $2 \mu \mathrm{M}$ LLMCA

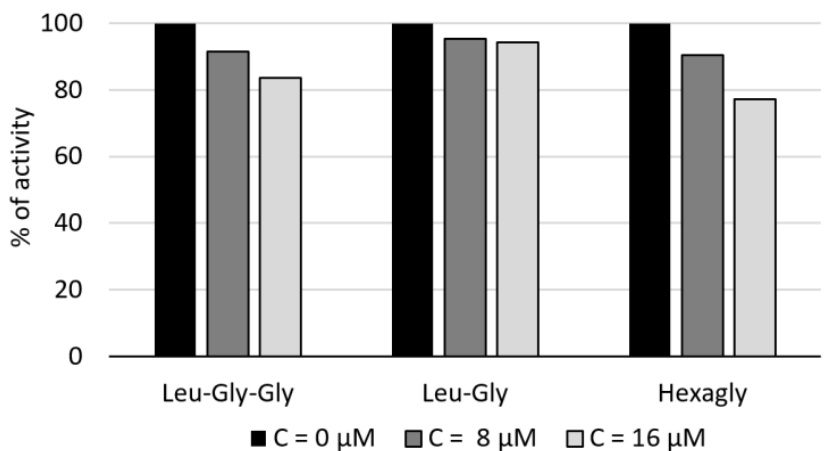

450

Fig. 8 : EPA measured using $0.125 \mu M$ LLMCA (a) or $2 \mu M$ LLMCA (b), with various concentrations of Leu-Gly-Gly, LeuGly or Hexagly, acting as competitors $(C)$. Results are measured in $\mathrm{mV} \mathrm{min}^{-1}$ and normalized by the maximum activity obtained without competitor.

Several other studies have shown the competition between natural and fluorogenic substrates when assaying APA (see for instance Chróst 1990; Fernley and Walker 1967; Hoppe 1983), EPA (Hoppe 1983; Somville and Billen 1983; Christian and Karl 1998) or glycosidases (Hoppe 1983; Somville 1984), which confirms our results showing that natural substrates may significantly alter the measured enzymatic activites at low analog substrate concentrations.

This issue arises from the legitimate need to measure in situ degradation rates. However, as natural substrates compete with the fluorogenic analog, those measurements are unreliable and depend on sample composition, which completely impedes inter-study comparison. It raises questions regarding what we really are interested in quantifying when measuring enzyme activity rates. Single point assays using a saturating substrate concentration ( $>10 \mathrm{~K}_{\mathrm{m}}$ ) allow the determination of a potential degradation rate $\left(\mathrm{V}_{\max }\right)$. This can be considered as a determination of enzyme concentration (Billen 1991). When it is normalized by the biomass or number of cells, it reflects the enzymatic equipment of the cells. Those measurements are comparable across studies and allow, for instance, to study the regulation of enzyme synthesis in response to environmental trophic conditions. In any case, fluorogenic substrate assays should be interpreted cautiously in terms of real substrate utilization, keeping in mind that activities are measured with respect to naturally occurring substrates (Billen 1991). 


\section{Conclusion and recommendations}

471 The starting point of this study was the comparison of existing literature on enzymatic activity measurement in aquatic environments. We noticed substantial divergences in existing methodologies, the most notable one being the difference in substrate concentrations used for assays. Furthermore, the occurrence of IFE, a fluorometric artifact, has never been considered despite being likely to occur, especially at saturating concentrations of substrate. Those factors might alter results and therefore, investigation of past articles and inter-study comparison should be carried out cautiously. In this study, we tried to highlight several methodological key points of enzymatic assays, illustrating them with APA and EPA, although results should apply to all fluorometric enzymatic assays.

(1) We would like to emphasize the possible occurrence of IFE, a fluorometric artifact that has been completely ignored in environmental water studies until now, despite having the potential to significantly affect measurements. In this study, it was not detected for APA assays but occurred for EPA assays with the two cuvette based spectrofluorometers tested, at a LLMCA threshold

(2) Ideally, before any single substrate assay, a kinetic analysis should be performed to determine concentration of $125 \mu \mathrm{M}$. This effect can also occur with microplate readers, to a lesser extent. IFE depends on sample dilution and the equipment used and can be corrected by using appropriate calibration curves. the apparent $\mathrm{K}_{\mathrm{m}}$ and to choose a saturating concentration. In practice, this step is laborious. However, when such experiments are carried out, a wide substrate concentration range (up to several hundred micromolar) should be used in order to reach the enzyme's active sites saturation and correctly fit both first and zero-order part of enzyme reaction. The maximum substrate concentration should be at least $10 \mathrm{~K}_{\mathrm{m}}$ to ensure that most enzymes are sufficiently saturated.

(3) Finally, when performing a single substrate assay, saturating substrate concentrations (> $10 \mathrm{~K}_{\mathrm{m}}$ ) should be preferred, rather than trace concentrations mimicking natural conditions. Indeed, this 
enzyme concentration) and may lead to higher uncertainties. Furthermore, it is highly dependent on both natural substrate concentrations and composition, as natural substrate might compete with the substrate analog for the enzyme active sites. Up to $34 \%$ and $38 \%$ inhibition was observed in the present study inhibition tests with natural substrates for EPA and APA, respectively.

501 All these methodological issues must be addressed in order to correctly measure enzymatic rates and 502 allow inter-study comparison. 
503

504

505

506

507

508

509

510

511

512

513

514

515

516

517

518

519

520

521

522

523

524

525

\section{References}

Arnosti, C. 2003. Microbial extracellular enzymes and their role in dissolved organic matter cycling. Aquat. Ecosyst. Interactivity dissolved Org. matter 342: 315-342. doi:10.1016/B978-0122563713/50014-7

Arnosti, C. 2011. Microbial extracellular enzymes and the marine carbon cycle. Ann. Rev. Mar. Sci. 3: 401-425. doi:10.1146/annurev-marine-120709-142731

Azam, F., T. Fenchel, J. G. Field, J. Gray, L. Meyer-Reil, and T. F. Thingstad. 1983. The Ecological Role of Water-Column Microbes in the Sea. Mar. Ecol. Prog. Ser. 10: 257-263. doi:10.3354/meps010257

Azam, F. 1998. Microbial control of oceanic carbon flux: The plot thickens. Science. 280: 694-696. doi:10.1126/science.280.5364.694

Bidle, K. D. 2010. Phytoplankton-Bacteria Interactions: Ectohydrolytic Enzymes and Their Influence on Biogeochemical Cycling. Limnol. Oceanogr. e-Lectures. doi:10.4319/lol.2010.kbidle.4

Billen, G. 1991. Protein Degradation in Aquatic Environments, p. 332. In R.J. Chróst [ed.], Microbial Enzymes in Aquatic Environments. Springer-Verlag, New York.

Bisswanger, H. 2014. Enzyme assays. Perspect. Sci. 1: 41-55. doi:10.1016/j.pisc.2014.02.005

Bogé, G., M. Lespilette, D. Jamet, and J. L. Jamet. 2012. Role of sea water DIP and DOP in controlling bulk alkaline phosphatase activity in N.W. Mediterranean Sea (Toulon, France). Mar. Pollut. Bull. 64: 1989-1996. doi:10.1016/j.marpolbul.2012.07.028

Briciu-burghina, C., B. Heery, and F. Regan. 2015. Continuous fluorometric method for measuring $\beta$ glucuronidase activity: comparative analysis of three fluorogenic substrates. Analyst 140: 59535964. doi:10.1039/c5an01021g

Bullock, A., K. Ziervogel, S. Ghobrial, S. Smith, B. McKee, and C. Arnosti. 2017. A multi-season investigation of microbial extracellular enzyme activities in two temperate coastal North Carolina 
rivers: Evidence of spatial but not seasonal patterns. Front. Microbiol. 8: 2589. doi:10.3389/fmicb.2017.02589

528

529

530

Carlsson, P., E. Granéli, W. Granéli, E. G. Rodriguez, W. F. de Carvalho, A. Brutemark, and E. Lindehoff. 2012. Bacterial and phytoplankton nutrient limitation in tropical marine waters, and a coastal lake in Brazil. J. Exp. Mar. Bio. Ecol. 418-419: 37-45. doi:10.1016/j.jembe.2012.03.012

Caruso, G., R. Caruso, and G. Maimone. 2019. Microbial enzymatic activity measurements by fluorogenic substrates: Evidence of inducible enzymes in oligotrophic Mediterranean areas. J. Clin. Microbiol Biochem. Technol. 5: 19-24. doi:10.17352/jcmbt

Chappell, K. R., and R. Goulder. 1995. A between-river comparison of extracellular-enzyme activity. Microb. Ecol. 29: 1-17. doi:10.1007/BF00217419

Christian, J. R., and D. M. Karl. 1998. Ectoaminopeptidase specificity and regulation in Antarctic marine pelagic microbial communities. Aquat. Microb. Ecol. 15: 303-310. doi:10.3354/ame015303

Christie, D. J., G. M. Alter, and J. A. Magnuson. 1978. Saccharide Binding to Transition Metal Ion Free Concanavalin A. Biochemistry 17: 4425-4430. doi:10.1021/bi00614a011

Chrost, R., and H. Krambeck. 1986. Fluorescence correction for measurements of enzyme activity in natural waters using methylumbelliferyl-substrates. Arch. Hydrobiol. 106: 79-90.

Chróst, R. J., and J. Overbeck. 1987. Kinetics of alkaline phosphatase activity and phosphorus availability for phytoplankton and bacterioplankton in Lake PluBsee (North German Eutrophic Lake). Microb. Ecol. 13: 229-248. doi:10.1007/BF02025000

Chróst, R. J. 1990. Microbial Ectoenzymes in Aquatic Environments, p. 47-77. In J. Overbeck and R.J. Chróst [eds.], Aquatic Microbial Ecology: Biochemical and molecular approaches. Springer Verlag, New York.

Chróst, R. J. 1991. Environmental Control of the Synthesis and Activity of Aquatic Microbial 
Cunha, M. A., M. A. Almeida, and F. Alcantara. 2001. Short-term responses of the natural planktonic bacterial community to the changing water properties in an estuarine environment: ectoenzymatic activity, glucose incorporation, and biomass production. Microb Ecol 42: 69-79. doi:10.1007/s002480000098

Davis, C. E., C. Mahaffey, G. A. Wolff, and J. Sharples. 2014. A storm in a shelf sea: Variation in phosphorus distribution and organic matter stoichiometry. Geophys. Res. Lett. 41: 8452-8459. doi:10.1002/2014GL061949

Delmas, D., C. Legrand, C. Bechemin, C. Collinot, C. Legrand, C. Bechemin, and C. Collinot Aquat. 1994. Exoproteolytic activity determined by flow injection analysis: its potential importance for bacterial growth in coastal marine ponds. Aquat. Living Resour 7: 17-24.

Delmas, D., and M. J. Garet. 1995. SDS-preservation for deferred measurement of exoproteolytic kinetics in marine samples. J. Microbiol. Methods 22: 243-248. doi:10.1016/01677012(95)00008-9

Duhamel, S., K. M. Björkman, J. K. Doggett, and D. M. Karl. 2014. Microbial response to enhanced phosphorus cycling in the North Pacific Subtropical Gyre. Mar. Ecol. Prog. Ser. 504: 43-58. doi:10.3354/meps10757

Eccleston, J. F., J. P. Hutchinson, and D. M. Jameson. 2005. Fluorescence-Based Assays. Prog. in Med. 454 Chem. 43: 19-48. doi: 10.1016/S0079-6468(05)43002-7

Fernley, H. N., and P. G. Walker. 1967. Studies on Alkaline Phosphatase - Inhibition by phosphate derivatives and the substrate specificity. Biochem. J. 104: 1011-1018. doi:10.11405/nisshoshi1964.71.784

Fonin, A. V., A. I. Sulatskaya, I. M. Kuznetsova, and K. K. Turoverov. 2014. Fluorescence of dyes in solutions with high absorbance. Inner filter effect correction. PLoS One. 
574

575

576

Fukuda, R., Y. Sohrin, N. Saotome, H. Fukuda, T. Nagata, and I. Koike. 2000. East-west gradient in ectoenzyme activities in the subarctic Pacific: Possible regulation by zinc. Limnol. Oceanogr. 45: 930-939. doi:10.4319/lo.2000.45.4.0930

Gonnelli, M., S. Vestri, and C. Santinelli. 2013. Chromophoric dissolved organic matter and microbial enzymatic activity. A biophysical approach to understand the marine carbon cycle. Biophys. Chem. 182: 79-85. doi:10.1016/j.bpc.2013.06.016

Guillard, R. R. L., and J. H. Ryther. 1962. Studies of marine planktonic diatoms. Can. J. Microbiol. 8: 229239.

Hoppe, H.-G. 1983. Significance of exoenzymatic activities in the ecology of brackish water: measurements by means of methylumbelliferyl-substrates. Mar. Ecol. Prog. Ser. 11: 299-308. doi:10.3354/meps011299

Hoppe, H.-G. 2003. Phosphatase activity in the sea. Hydrobiologia 187-200. doi:10.1023/a:1025453918247

Kao, S., A. N. Asanov, and P. B. Oldham. 1998. A comparison of fluorescence inner-filter effects for different cell configurations. Instrum. Sci. Technol. 26: 375-387. doi:10.1080/10739149808001906

Karl, D. M., and K. M. Björkman. 2015. Dynamics of Dissolved Organic Phosphorus, p 233-334. In D. A. Handsell and C. A. Carlson [eds.], Biogeochemistry of marine dissolved organic matter: Second Edition. Academic Press, Amsterdam.

Karner, M., D. Fuks, and G. J. Herndl. 1992. Bacterial activity along a trophic gradient. Microb. Ecol. 24: 243-257. doi:10.1007/BF00167784

Keil, R. G., and D. L. Kirchman. 1991. Dissolved combined amino acids in marine waters as determined 
by a vapor-phase hydrolysis method. Mar. Chem. 33: 243-259. doi:10.1016/03044203(91)90070-D

Kirchman, D. L. 2008. Microbial Ecology of the Oceans: Second Edition. Wiley-Blackwell, Hoboken. 477 $593 p$.

Koch, M. S., D. C. Kletou, and R. Tursi. 2009. Alkaline phosphatase activity of water column fractions and seagrass in a tropical carbonate estuary, Florida Bay. Estuar. Coast. Shelf Sci. 83: 403-413.

Kothawala, D. N., K. R. Murphy, C. A. Stedmon, G. A. Weyhenmeyer, and L. J. Tranvik. 2013. Inner filter correction of dissolved organic matter fluorescence. Limnol. Oceanogr. Methods 11: 616-630. doi:10.4319/lom.2013.11.616

Labry, C., D. Delmas, and A. Herbland. 2005. Phytoplankton and bacterial alkaline phosphatase activities in relation to phosphate and DOP availability within the Gironde plume waters (Bay of Biscay). J. Exp. Mar. Bio. Ecol. 318: 213-225. doi:10.1016/j.jembe.2004.12.017

Labry, C., D. Delmas, A. Youenou, J. Quere, A. Leynaert, S. Fraisse, M. Raimonet, and O. Ragueneau. 2016. High alkaline phosphatase activity in phosphate replete waters: The case of two macrotidal

Liu, Y., W. Kati, C. M. Chen, R. Tripathi, A. Molla, and W. Kohlbrenner. 1999. Use of a fluorescence plate reader for measuring kinetic parameters with inner filter effect correction. Anal. Biochem. 267:

Marathe, B. M., V. Lévêque, K. Klumpp, R. G. Webster, and E. A. Govorkova. 2013. Determination of 331-335. doi:10.1006/abio.1998.3014 

matter distribution (Ross sea, Antarctica). Microb. Ecol. 44: 224-234. doi:10.1007/s00248-0022017-9

622

Nausch, M., G. Nausch, and N. Wasmund. 2004. Phosphorus dynamics during the transition from nitrogen to phosphate limitation in the central Baltic Sea. Mar. Ecol. Prog. Ser. 266: 15-25. doi:10.3354/meps266015

Niell, F. X., B. a Whitton, and I. Hernández. 2003. Phosphatase activity of benthic marine algae. An overview. J. Appl. Phycol. 3: 475-487.

Ory, P., S. Palesse, D. Delmas, and H. Montanié. 2011. In situ structuring of virioplankton through bacterial exoenzymatic activity: interaction with phytoplankton. Aquat. Microb. Ecol. 64: 233252. doi:10.3354/ame01524

Palmier, M. O., and S. R. Van Doren. 2007. Rapid determination of enzyme kinetics from fluorescence: Overcoming the inner filter effect. Anal. Biochem. 371: 43-51. doi:10.1016/j.ab.2007.07.008

Patel, A. B., K. Fukami, and T. Nishijima. 2000. Regulation of seasonal variability of aminopeptidase activities in surface and bottom waters of Uranouchi Inlet, Japan. Aquat. Microb. Ecol. 21: 139149. doi:10.3354/ame021139

Payne, J. W., ed. 1980. Microorganisms and nitrogen sources : transport and utilization of amino acids, peptides, proteins, and related substrates. John Wiley, New York. 870p.

Pinto, M. F., B. N. Estevinho, R. Crespo, F. A. Rocha, A. M. Damas, and P. M. Martins. 2015. Enzyme kinetics: The whole picture reveals hidden meanings. FEBS J. 282: 2309-2316. doi:10.1111/febs.13275

Puchalski, M. M., M. J. Morra, and R. von Wandruszka. 1991. Assessment of inner filter effect corrections in fluorimetry. Fresenius. J. Anal. Chem. 340: 341-344. doi:10.1007/BF00321578 
644

645

646

Rees, A. P., S. B. Hope, C. E. Widdicombe, J. L. Dixon, E. M. S. Woodward, and M. F. Fitzsimons. 2009. Alkaline phosphatase activity in the western English Channel: Elevations induced by high summertime rainfall. Estuar. Coast. Shelf Sci. 81: 569-574. doi:10.1016/j.ecss.2008.12.005

Ridal, J. J., and R. M. Moore. 1992. Dissolved organic phosphorus concentrations in the northeast subarctic Pacific Ocean. Limnol. Oceanogr. 37: 1067-1075. doi:10.4319/lo.1992.37.5.1067

Rinker, K. R., and R. T. Powell. 2006. Dissolved organic phosphorus in the Mississippi River plume during spring and fall 2002. Mar. Chem. 102: 170-179. doi:10.1016/j.marchem.2005.09.013

Saifuku, K., T. Sekine, T. Namihisa, T. Takahashi, and Y. Kanaoka. 1978. A novel fluorometric ultramicro determination of serum leucine aminopeptidase using a coumarine derivative. Clin. Chim. Acta 84: 85-91. doi:10.1016/0009-8981(78)90479-5

Sala, M. M., M. Karner, L. Arin, and C. Marrasé. 2001. Measurement of ectoenzyme activities as an indication of inorganic nutrient imbalance in microbial communities. Aquat. Microb. Ecol. 23: 301-311. doi:10.3354/ame023301

Sebastián, M., and F. X. Niell. 2004. Alkaline phosphatase activity in marine oligotrophic environments: Implications of single-substrate addition assays for potential activity estimations. Mar. Ecol. Prog. Ser. 277: 285-290. doi:10.3354/meps277285

Shi, Z., J. Xu, X. Li, R. Li, and Q. Li. 2019. Links of Extracellular Enzyme Activities, Microbial Metabolism, and Community Composition in the River-Impacted Coastal Waters. J. Geophys. Res. Biogeosciences 124: 3507-3520. doi:10.1029/2019JG005095

Sinsabaugh, R. L., S. Findlay, P. Franchini, and D. Fischer. 1997. Enzymatic analysis of riverine bacterioplankton production. Limnol. Oceanogr. 42: 29-38. doi:10.4319/lo.1997.42.1.0029 

doi:10.3389/fmicb.2019.01913

668

669

670

Sohm, J. A., and D. G. Capone. 2006. Phosphorus dynamics of the tropical and subtropical north Atlantic: Trichodesmium spp. versus bulk plankton. Mar. Ecol. Prog. Ser. 317: 21-28. doi:10.3354/meps317021

Somville, M. 1984. Measurement and study of substrate specificity of Exoglucosidase activity in eutrophic water. Appl. Environ. Microbiol. 48: 1181-1185.

Somville, M., and G. Billen. 1983. A method for determining exoproteolytic activity in natural waters. Limnol. Oceanogr. 28: 190-193. doi:10.4319/lo.1983.28.1.0190

Song, C., X. Cao, Y. Zhou, and others. 2019. Nutrient regeneration mediated by extracellular enzymes in water column and interstitial water through a microcosm experiment. Sci. Total Environ. 670: 982-992. doi:10.1016/j.scitotenv.2019.03.297

Steen, A. D., J. P. Vazin, S. M. Hagen, K. H. Mulligan, and S. W. Wilhelm. 2015. Substrate specificity of aquatic extracellular peptidases assessed by competitive inhibition assays using synthetic substrates. Aquat. Microb. Ecol. 75: 271-281. doi:10.3354/ame01755

Štrojsová, A., J. Nedoma, M. Štrojsová, X. Cao, and J. Vrba. 2008. The role of cell-surface-bound phosphatases in species competition within natural phytoplankton assemblage: An in situ experiment. J. Limnol. 67: 128-138. doi:10.4081/jlimnol.2008.128

Talbot, V., L. Giuliano, V. Bruni, and M. Bianchi. 1997. Bacterial abundance, production and ectoproteolytic activity in the Strait of Magellan. Mar. Ecol. Prog. Ser. 154: 293-302. doi:10.3354/meps154293

Thingstad, T. F., U. L. Zweifel, and F. Rassoulzadegan. 1998. P limitation of heterotrophic bacteria and phytoplankton. Limnol. Oceanogr. 4: 88-94. 
689 Valeur, B. 2001. Molecular fluorescence, principles and application. Wiley, Weinheim. 381p.

690 Van Wambeke, F., U. Christaki, A. Giannakourou, T. Moutin, and K. Souvemerzoglou. 2002. 691 Longitudinal and vertical trends of bacterial limitation by phosphorus and carbon in the 692 Mediterranean Sea. Microb. Ecol. 43: 119-133. doi:10.1007/s00248-001-0038-4

693 Van Wambeke, F., J.-F. Ghiglione, J. Nedoma, G. Mével, and P. Raimbault. 2009. Bottom up effects on 694 bacterioplankton growth and composition during summer-autumn transition in the open NW 695 Mediterranean Sea. Biogeosciences 6: 705-720. doi:10.5194/bg-6-705-2009

696 Yamaguchi, T., M. Sato, F. Hashihama, M. Ehama, T. Shiozaki, K. Takahashi, and K. Furuya. 2019. Basin697 Scale Variations in Labile Dissolved Phosphoric Monoesters and Diesters in the Central North Pacific Ocean. J. Geophys. Res. Ocean. 124: 3058-3072. doi:10.1029/2018JC014763

699 
Fig. 1. Fig. 1. (A) Normalized fluorescence spectra of MUF-P (alkaline phosphatase substrate, dashed lines) and MUF (product, solid lines) over emission (gray lines) or excitation wavelength (black lines). Excitation spectra of MUF and MUF-P were obtained using a constant emission wavelength (460 nm) while excitation wavelength varied. Emission spectra were obtained using a constant excitation wavelength $(364 \mathrm{~nm})$ with variable emission wavelength. (B) Normalized fluorescence spectra of LLMCA (protease substrate, dashed lines) and MCA (product, solid lines) over emission (gray lines) or excitation wavelength (black lines). To obtain excitation spectra of MCA and LLMCA, emitted light was respectively collected at a wavelength of 440 and $410 \mathrm{~nm}$ while excitation wavelength varied. To obtain emission spectra, emitted light was collected over a range of wavelength while excitation wavelength was set to 350 and $325 \mathrm{~nm}$ for MCA and LLMCA, respectively. em: emission, ex: excitation. Vertical lines represent excitation and emission wavelengths used during enzymatic assays.

Fig. 2. Conceptual illustration of excitation IFE (also termed primary IFE) and emission IFE (also termed secondary IFE) using a right angle geometry, one of the most common for cuvette system.

Table 1. Literature examples showing phosphatase activity assay conditions used in different environments. All measurements were carried out using 4-Methylumbelliferyl phosphate (MUF-P) substrate.

Table 2. Literature examples showing exoproteolytic activity assay conditions used in different environments. All measurements were carried out using L-Leucine-7-amido-4-methylcoumarin (LLMCA) substrate.

Fig. 3. Detection of IFE using calibration curves of MUF (a, c, e) and MCA (b, d, f), with cuvette operated LS50 spectrofluorometer. Calibration curves (a, b) were determined from solutions prepared in varying concentration of non-hydrolysed substrate (MUF-P, LLMCA). On panel a and b, only four calibration curves are shown to facilitate readability although 12 and 9 curves were respectively measured for APA and EPA. All calibrations are displayed on other panels. Calibration of MUF shows no IFE as the slope of each calibration is not dependent on MUF-P concentration (c) and intercept varies 
linearly with MUF-P concentration (e). Calibration of MCA exhibits an IFE as the slope of each calibration varies significantly with LLMCA concentration (d) and intercept does not vary linearly above $60 \mu \mathrm{M}$ of LLMCA (f). $r$ : correlation coefficient.

Fig. 4. (a) Kinetics of natural bacterial communities EPA measured using FIA-SFM25 (black line) or with LS50 (using cuvette, grey line). (b) Correlation between EPA measured with LS50 (using cuvette) and using FIA-SFM25. Dashed line highlights the substrate concentration threshold.

Fig. 5. Evolution of kinetic parameters $\left(\mathrm{V}^{\mathrm{n}}{ }_{\max }, \mathrm{K}^{\mathrm{n}}{ }_{\mathrm{m}}\right)$ of purified E. coli alkaline phosphatase over the maximum substrate concentration $\left(\mathrm{S}_{\max }\right)$ used. Several fittings were done on the same assay data, iteratively removing the highest substrate concentration. Correlation coefficient indicated significant results for $\mathrm{n}>4($ at $0.1 \%)$.

Fig. 6. Normalized $\mathrm{V}_{\max }\left(\mathrm{V}^{\mathrm{n}}{ }_{\max } / \mathrm{V}^{\mathrm{t}}{ }_{\max }\right)$ over normalized maximum substrate concentration $\left(\mathrm{S}_{\max } / \mathrm{K}_{\mathrm{m}}^{\mathrm{t}}\right)$ of APA assays conducted on various samples (purified enzymes from shrimp and E. coli, cultures of T. weissflogii and A. minutum and natural bacterial communities). Each dot represent a non-linear fitting done on the same kinetic experiment data, but iteratively reducing $S_{\max }$, which is represented normalized on the X-axis. Velocities are normalized by the "true" $V_{\text {max }}^{t}$ obtained at $S_{\max }=500 \mu \mathrm{M}$ and substrate concentrations are normalized by the "true" $\mathrm{K}_{\mathrm{m}}^{\mathrm{t}}$ obtained at $\mathrm{S}_{\max }=500 \mu \mathrm{M}$.

Fig. 7. APA measured using trace MUF-P concentrations with various concentrations of G6P, a natural non-fluorescent competitor. Results are given in $\mathrm{mV} \min ^{-1}$ and normalized by the maximum activity obtained for each MUF-P concentration (without competitor).

Fig. 8. EPA measured using $0.125 \mu \mathrm{M}$ LLMCA (a) or $2 \mu \mathrm{M}$ LLMCA (b), with various concentrations of Leu-Gly-Gly, Leu-Gly or Hexagly, acting as competitors (C). Results are measured in $\mathrm{mV} \mathrm{min}^{-1}$ and normalized by the maximum activity obtained without competitor. 


\section{Acknowledgments}

750 This work was supported by the French National Program for Coastal Environment (EC2CO) and by

751 the ISblue project, Interdisciplinary graduate school for the blue planet (ANR-17-EURE-0015), co-

752 funded by a grant from the French government under the program "Investissements d'Avenir". We wish

753 to thank M. Latimier for the preparation of phytoplankton cultures. 